\title{
Toxicodermias I
}

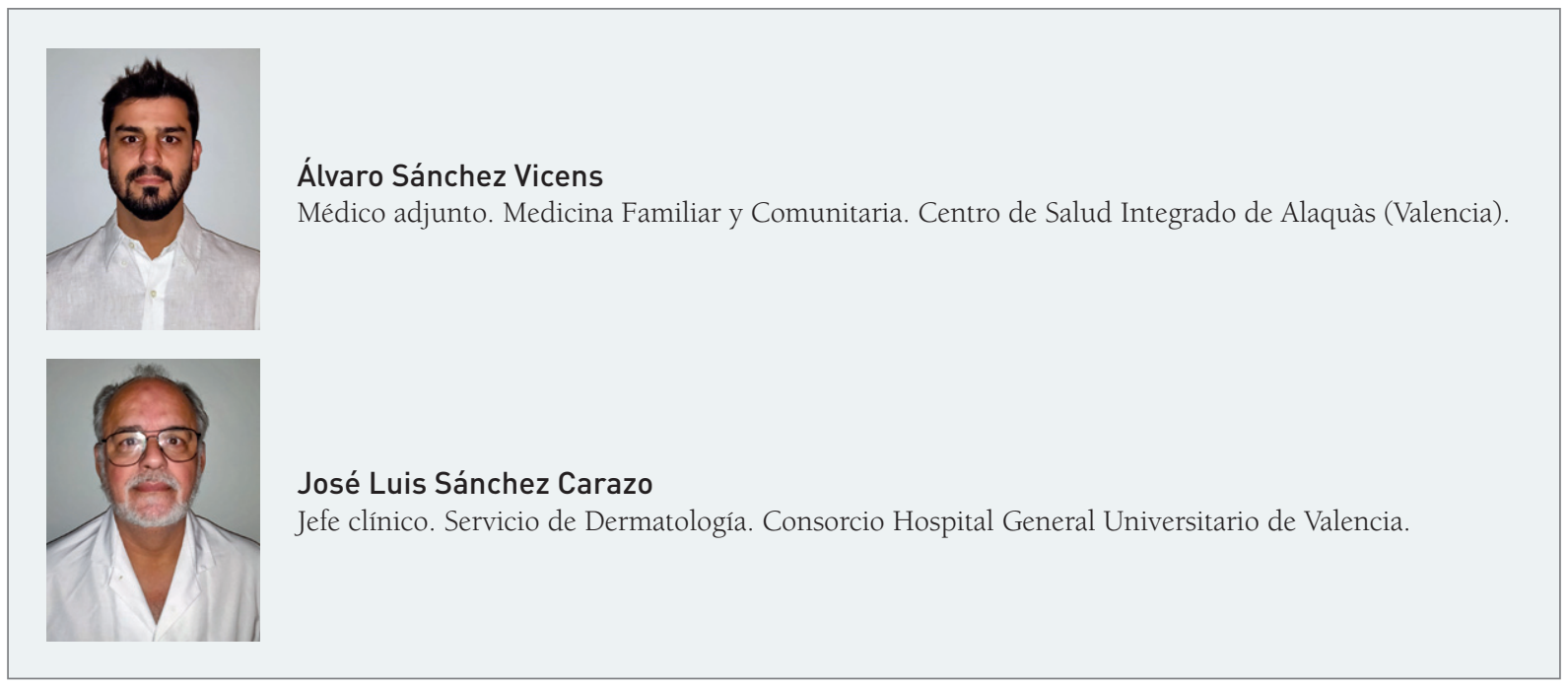

\section{RESUMEN}

Dado el aumento de supervivencia y tratamientos, hay un elevado uso de fármacos, lo que conlleva el incremento de la frecuencia de las reacciones adversas medicamentosas. De todas ellas, las que afectan a la piel son las más frecuentes. La mayoría de ellas, no obstante, son benignas, y son estas las que revisaremos aquí: urticaria aguda y angioedema (cuadros mediados por inmunoglobulina E), erupción maculopapular benigna inducida por fármacos (la más frecuente), exantema simétrico flexural e intertriginoso relacionado con fármacos (infrecuente y autolimitado) y erupción fija por fármacos (lesiones recurrentes en las mismas localizaciones, tras nuevas exposiciones al fármaco).

\section{INTRODUCCIÓN}

Se denomina toxicodermia al conjunto de reacciones en la piel, mucosas y/o anejos causadas por medicamentos que entran en el cuerpo ${ }^{1}$.
Las reacciones adversas debidas a fármacos representan un importante problema de salud; aproximadamente, hasta el 15\% de pacientes tienen una reacción adversa, entre el 2 y el $5 \%$ deben ser hospitalizados y, en el 1-3\% de los casos, el episodio puede ser mortal ${ }^{2}$.

Como resultado del aumento de la edad poblacional general y la efectividad de herramientas diagnósticas más avanzadas, han mejorado los resultados terapéuticos, incrementándose la supervivencia de los pacientes; ello conlleva la existencia de tratamientos crónicos, más prolongados y, por lo tanto, la aparición de polifarmacia en una población envejecida. La exposición a fármacos ha crecido tanto en frecuencia como en duración, generando un aumento de la multimorbilidad, especialmente, en poblaciones ancianas. La polifarmacia es uno de los principales factores de riesgo para la interacción farmacológica y las reacciones adversas medicamentosas $(\mathrm{RAM})^{3}$.

Como consecuencia directa de este fenómeno, aumenta la probabilidad de que ocurra una sensibilización a fármacos, con un consiguiente incre- 
mento de las tasas de RAM. De todas las RAM, el órgano más frecuentemente afectado es la piel.

Los fármacos que producen la mayoría de reacciones alérgicas son antibióticos, antiinflamatorios y anticomiciales, aunque cualquier fármaco puede provocar una toxicodermia.

La gran mayoría de reacciones adversas cutáneas o toxicodermias son de características benignas, siendo, generalmente, erupciones maculopapulares o urticariformes. Únicamente el $2 \%$ de las erupciones cutáneas son realmente peligrosas para la vida ${ }^{4}$. De hecho, una toxicodermia de características benignas no obliga a contraindicar el fármaco responsable.

Existen múltiples mecanismos por los cuales los fármacos pueden producir toxicidad: mecanismos no inmunitarios como sobredosis, efectos secundarios farmacológicos, toxicidad acumulada, toxicidad diferida, interacciones fármaco-fármaco, alteraciones del metabolismo, reagudización de la enfermedad.

Nos centraremos, fundamentalmente, en las reacciones a fármacos con mecanismo inmunitario, dependientes de inmunoglobulina E (IgE): urticaria, angioedema y anafilaxia; las reacciones a fármacos idiosincrásicas con un posible mecanismo inmunitario mediadas por células, y las erupciones exantemáticas a fármacos, consideradas como reacciones leves sin compromiso vital.

\section{CUADROS BENIGNOS}

\section{Urticaria y angioedema mediados por inmunoglobulina $\mathrm{E}$}

Menos del 10\% de los casos de urticaria se deben a fármacos, aunque estos se asocian con más frecuencia a urticaria crónica.

La urticaria mediada por IgE tiene una aparición rápida, a los pocos minutos de haber tomado el medicamento en personas previamente sensibilizadas.

Clínicamente, aparecen pápulas y placas eritematosas y edematosas transitorias, habitualmente, pruriginosas, de tamaño y número muy variables, que pueden agruparse. Se debe a un edema por vasodilatación de la dermis, mediada por mastocitos cutáneos, que liberan histamina. Los fármacos que producen urticaria inmunitaria con más frecuencia son los antibióticos, en especial, las penicilinas y las cefalosporinas.

El tratamiento consiste en la retirada del fármaco y la administración de antihistamínicos.

Los análisis inmunológicos, como las pruebas de radioalergoadsorción (RAST; del inglés, radioallergosorbent test), que detectan anticuerpos IgE específicos, y las pruebas cutáneas (pruebas de contacto) pueden ser útiles para confirmar el diagnóstico ${ }^{4}$.

El angioedema es un cuadro agudo que puede ser mortal. El edema se localiza en la dermis profunda y en el tejido subcutáneo y submucoso. Se asocia a urticaria en la mitad de las ocasiones. La clínica se presenta como una tumefacción facial generalmente, aunque pueden existir manifestaciones sistémicas por afectación de la pared abdominal. El edema laríngeo es la expresión más grave.

Es frecuente el angioedema inducido por inhibidores de la enzima convertidora de la angiotensina (ECA). La ECA es una enzima clave responsable de la inactivación de la bradicinina, y su bloqueo por los inhibidores de la ECA puede desencadenar ataques agudos de angioedema. Las lesiones pueden aparecer desde un día hasta varios años después de iniciar su administración. Otros fármacos frecuentemente involucrados son los antiinflamatorios no esteroideos (AINE), los medios de contraste radiológico y los anticuerpos monoclonales ${ }^{4}$.

\section{Erupción maculopapular benigna inducida por fármacos}

Son las reacciones de hipersensibilidad más frecuentes. Se presentan clínicamente como una erupción maculopapular (MPR; del inglés, maculopapular rash), caracterizada por máculas y/o pápulas eritematosas, que se distribuyen simétricamente en el tronco y las extremidades; aparecen con mayor frecuencia en el tronco ventral y dorsal antes de expandirse a las extremidades proximales (fig. 1). En 
la MPR, las mucosas están afectadas. También pueden presentarse en un patrón de tipo eccematoide, psoriasiforme o liquenoide.

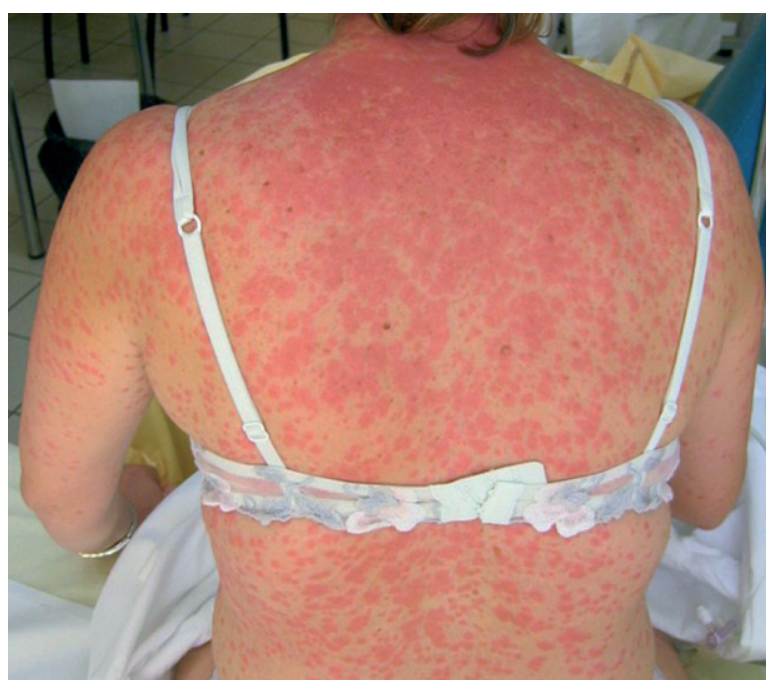

FIGURA 1. Erupción maculopapular benigna por fármacos.

Cuando la persona se expone al fármaco por primera vez, la erupción cutánea se retrasará hasta después de una fase de sensibilización de, al menos, 5-7 días. En pacientes previamente expuestos y sensibilizados, la aparición de las primeras lesiones cutáneas ocurre en el plazo de 6 a 12 horas.

Los agentes farmacológicos responsables de la mayoría de las reacciones adversas cutáneas incluyen antibióticos, fármacos antiinfecciosos y tuberculostáticos, así como agentes anticonvulsivos y antihipertensivos ${ }^{5}$.

Los corticoides tópicos y los antihistamínicos sistémicos para aliviar los síntomas - especialmente, el control del prurito- pueden ser útiles. En casos más graves, es necesario el tratamiento con corticoides sistémicos.

El tipo IVb corresponde a una respuesta inmunitaria de tipo $\mathrm{T}_{\mathrm{h}} 2$ (linfocitos $\mathrm{T}$ colaboradores de tipo 2; del inglés, $T$ helper cell 2), que involucra en particular a las citocinas interleucina 4 (IL-4), 13 (IL-13) y 5 (IL-5), que promueven la expansión de los linfocitos B y la posterior activación de las cé- lulas plasmáticas, con producción de IgE e IgG4. Este mecanismo patógeno de tipo IVb puede explicar la inflamación rica en eosinófilos que se puede observar en muchos exantemas inducidos por fármacos.

Existen cuadros que tienen en común el aspecto fotodistribuido de las lesiones y su aparición tras la exposición solar. Se trata de cuadros fototóxicos, al activar la luz la molécula en pacientes predispuestos, y se asemeja a una quemadura solar tras la exposición al sol. Los fármacos más frecuentes son las tetraciclinas, las fenotiacinas y fluoroquinolonas ${ }^{6}$.

\section{Exantema intertriginoso y flexural simétrico relacionado con fármacos}

El exantema intertriginoso y flexural simétrico relacionado con fármacos (SDRIFE; del inglés, symmetrical drug-related intertriginous and flexural exanthema) es una erupción eritematosa simétrica, localizada en las áreas glútea e intertriginosa, con la afectación de los grandes pliegues cutáneos, como la axila (fig. 2), los codos y las rodillas, que se observa después de la exposición a fármacos sistémicos. Es un cuadro infrecuente, considerándose una erupción benigna debido a su curso autolimitado, y las complicaciones son excepcionales ${ }^{7}$.

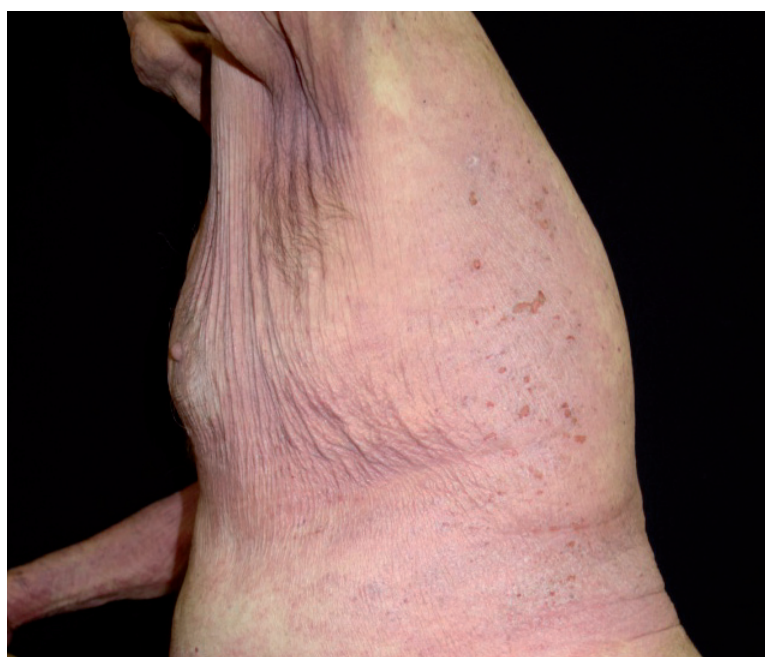

FIGURA 2. Exantema intertriginoso y flexural simétrico relacionado con fármacos. 
Los medicamentos que con más frecuencia causan SDRIFE son los antibióticos betalactámicos, especialmente, la amoxicilina, si bien, se han descrito con múltiples fármacos.

El mecanismo patogénico no está aclarado; es probable que el SDRIFE implique tanto una reacción de tipo IVa, mediada por células $C D 4+T_{h} 1$ y macrófagos, como también un tipo de reacción IVc, con linfocitos T citotóxicos CD4 y CD8. Esto no explica la aparición de SDRIFE después de la primera exposición a un fármaco determinado sin sensibilización ${ }^{8}$.

El diagnóstico se basa en el aspecto característico de la erupción: la afectación de las áreas intertriginosas y glúteas y la simetría de las lesiones; eritema o placas bien delimitadas que afectan al área glútea, perianal, inguinal o perigenital, con descamación importante y con ausencia de síntomas sistémicos. Pueden aparecer cuadros atípicos con pústulas, pápulas y ampollas. No se ven afectadas las mucosas y la afectación palmoplantar es excepcional ${ }^{9}$.

La histología es inespecífica, con un infiltrado perivascular superficial de células mononucleares y presencia de neutrófilos y eosinófilos.

El diagnóstico se puede realizar por medio del parche cutáneo, que da una reacción positiva solo hasta en el $50 \%$ de los pacientes.

Las pruebas controladas de provocación se consideran la técnica de referencia y son positivas en la mayoría de los pacientes con SDRIFE.

\section{Erupción fija por fármacos}

El cuadro se define por la aparición de lesiones recurrentes tras la ingesta repetida de un fármaco. La característica patognomónica es la recurrencia en la misma localización ante la reexposición al agente causal.

Clínicamente, se caracteriza por la aparición de máculas redondeadas eritematosas o de color rojo violáceo, solitarias y escasas, bien definidas, con límites marcados, a veces, centradas por una ampolla o un punto necrótico (fig. 3). Las localizaciones frecuentes son los labios, las manos, los genitales (especialmente, los genitales masculinos) y, ocasio- nalmente, la mucosa oral, aunque las lesiones pueden encontrarse en cualquier parte de la piel y las mucosas.

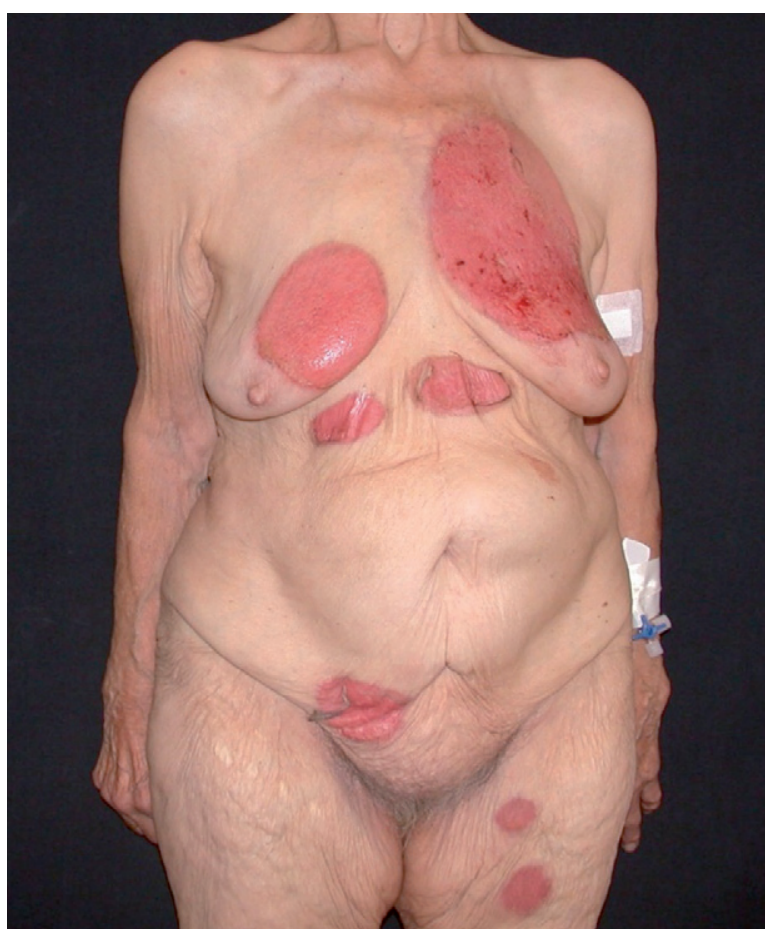

FIGURA 3. Erupción fija por fármacos.

Se suele resolver dejando una mácula hiperpigmentada en el área afectada. Si encontramos lesiones múltiples, se pueden asociar a síntomas sistémicos, con fiebre, náuseas, malestar y artralgias. El mecanismo lesional está relacionado en parte con los linfocitos T de memoria residente en el tejido (TRM; del inglés, tissue-resident memory $\mathrm{T}$ cell), lo que explica parcialmente la recurrencia en los mismos lugares. Los agentes causales más frecuentes son la pseudoefedrina, la trimetoprima, las tetraciclinas, los barbitúricos, las sulfonamidas, el ácido acetilsalicílico y el ibuprofeno ${ }^{10}$.

Histopatológicamente, se encuentran queratinocitos necróticos y disqueratósicos, con espongiosis y vacuolización de la capa basal, edema en la dermis y un infiltrado linfohistiocitario perivascular e intersticial, con algunos eosinófilos. Es característica 
Toxicodermias I

la presencia de incontinencia pigmentaria, con macrófagos melanófagos cargados de melanina en la dermis papilar.

En las formas ampolloso-necróticas, pueden existir vesículas y ampollas subepidérmicas con necrosis de la epidermis suprayacente.

El tratamiento es sintomático, con la supresión del fármaco y la administración de corticoides tópicos y antihistamínicos. Los corticoides orales se han usado en casos ampollosos graves, pero no alteran la evolución del cuadro.

\section{BIBLIOGRAFÍA}

1. Roujeau JC, Bonnetblanc JM, Schmutz JL, Crickx B. Iatrogénie. Diagnostic et prévention. Toxidermies médicamenteuses. Ann Dermatol Venereol. 2002;129(10 Suppl):S163-9.

2. Demoly P, Hillaire-Buys D. Classification and epidemiology of hypersensitivity drug reactions. Immunol Allergy Clin North Am. 2004;24(3):345-56

3. Field TS, Gurwitz JH, Avorn J, McCormick D, Jain S, Eckler M, et al. Risk factors for adverse drug events among nursing home residents. Arch Intern Med. 2001;161(13):1629-34.
4. The diagnosis and management of anaphylaxis. Joint Task Force on Practice Parameters, American Academy of Allergy, Asthma and Immunology, American College of Allergy, Asthma and Immunology, and the Joint Concil of Allergy, Asthma and Immunology. J Allergy Clin Immunol. 1998;101(6 Pt 2):S465-528.

5. Bigby M, Jick S, Jick H, Arndt K. Drug-induced cutaneous reactions. A report from the Boston Collaborative Drug Surveillance Program on 15,438 consecutive inpatients, 1975 to 1982. JAMA. 1986;256(24):3358-63

6. Bourrain JL. Toxidermies. Ann Dermatol Venereol. 2019;146(11): 740-55.

7. Nespoulous L, Matei I, Charissoux A, Bédane C, Assikar S. Symmetrical drug-related intertriginous and flexural exanthema (SDRIFE) associated with pristinamycin, secnidazole, and nefopam, with a review of the literature. Contact Dermatitis. 2018; 79(6):378-80

8. Huynh T, Hughey LC, McKay K, Carney C, Sami N. Systemic drug-related intertriginous and flexural exanthema from radio contrast media: a series of 3 cases. JAAD Case Rep. 2015;1(3): 147-9.

9. Tan SC, Tan JWL. Symmetrical drug-related intertriginous and flexural exanthema. Curr Opin Allergy Clin Immunol. 2011; 11(4):313-8.

10. Mizukawa Y, Yamazaki Y, Teraki Y, Hayakawa J, Hayakawa K, Nuriya $\mathrm{H}$, et al. Direct evidence for interferon-gamma production by effector-memory-type intraepidermal $\mathrm{T}$ cells residing at an effector site of immunopathology in fixed drug eruption. Am J Pathol. 2002;161(4):1337-47. 